\title{
Simplified Method for Stablization of Bonded Lingual Retainer
}

\author{
Dr Raju Shrestha,' Dr Hemant Kumar Halwai, ${ }^{2}$ Dr Sumit Kumar Yadav, ${ }^{3}$ Dr Kishor Dutta \\ 'Resident, ${ }^{2.3}$ Assoc Prof, ${ }^{4}$ Asst Prof, Dept of Orthodontics, \\ Universal College of Dental Surgery, Bhairahawa, Nepal
}

Correspondence: Dr Raju Shrestha; Email: rajushrestha19891@gmail.com

\section{ABSTRACT}

After completion of orthodontic treatment, retention is the most important step for prevention of relapse. Many direct and indirect techniques for placing a bonded lingual retainer have been practiced over the years. Present clinical practice demands a convenient technique for bonding a lingual retainer. This article describes a simplified technique of bonding a lingual retainer.

\section{INTRODUCTION}

Permanent maintenance of the result achieved from successful orthodontic treatment of malocclusion is of utmost importance to orthodontic clinician. Fixed lingual bonded retainers are widely used today for differentiated retention and provide excellent results if proper bonding and stabilizing technique are followed.' Clinical experience and differential retention philosophy have demonstrated the need for two types of bonded wire retainer: thick (0.030" or 0.032" diameter) and thin multistranded (0.0215" diameter). The thick wire is used for a mandibular 3-3 retainer bonded only on terminal dental units; whereas the thin spiral wire is used for various retainers in which all teeth in the segment are bonded. ${ }^{2}$ The following method provides a simple technique for stablization of bonded lingual retainer without the need for special instrument and aided assistance.

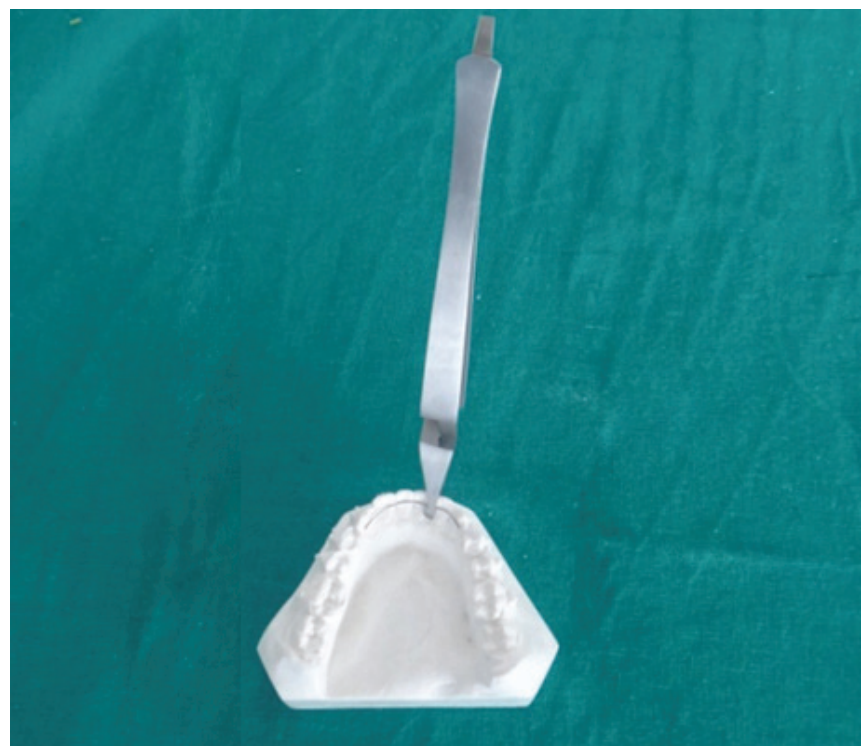

Figure 1: Flexible spiral wire adapted on dental model

\section{METHOD}

1. On working model, using a fine wire bending plier, adapt 0.0215 (thin) or 0.030/0.032 (thick) flexible spiral wire and cut to required length (Figure 1).

2. Check the retainer on patient for good fit in passive state and adjust accordingly (Figure 2).

3. After etching the lingual surface of the teeth to be bonded, the retainer is stabilized in place on passive state with the help of reverse bracket holding tweezer (Figure 3).

4. Retainer is bonded on the canine area with light cure or chemically cured composite resin.

5. After bonding in canine region, once the stability is achieved tweezer is removed and retainer is checked for passive tension.

6. If the wire is passive remaining teeth are bonded (Figure 4).

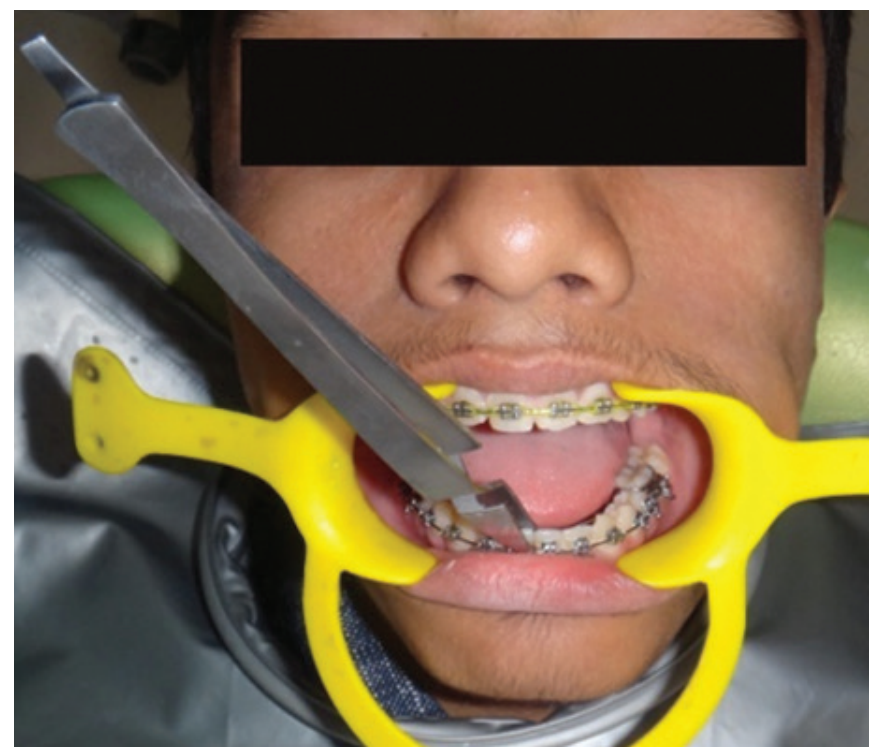

Figure 2: Fixed retainer stabilized intra-orally 


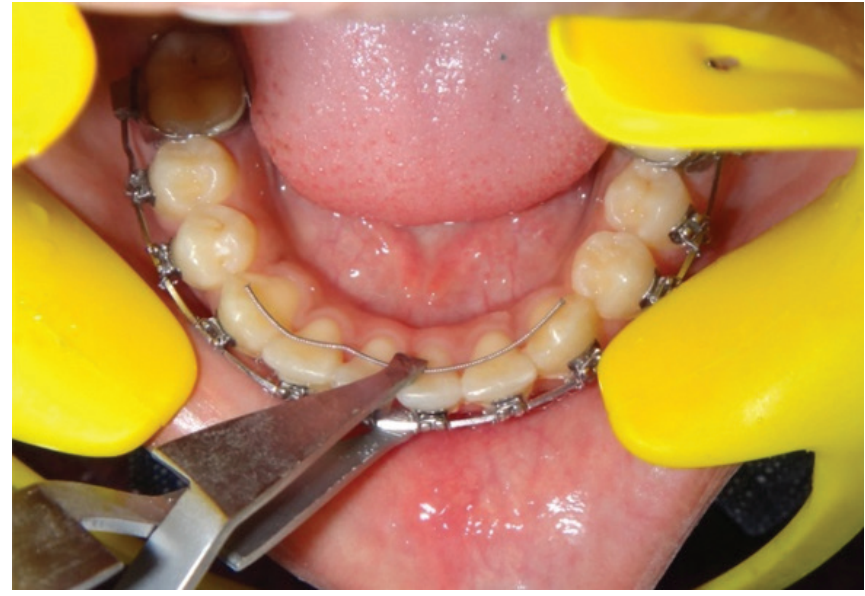

Figure 3: Stabilization achieved with tweezer

\section{DISCUSSION}

Studies of untreated normal occlusion have shown that the arch length decreases and mandibular incisor crowding increases throughout life. ${ }^{3}$ This has led many orthodontists to conclude that the only way to maintain the ideal alignment after treatment is some form of permanent retention with fixed bonded retainers. ${ }^{4}$ One of the common problems with bonded lingual retainer is to

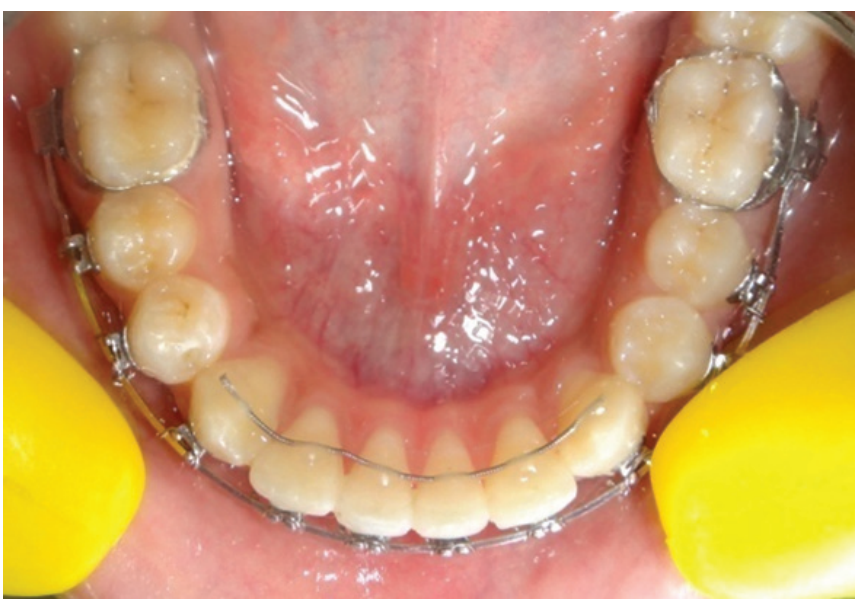

Figure 4: Bonding completed

achieve proper stabilization while performing the bonding. Various methods for stablization of fixed lingual retainer has been described.5,6 The above method provides a convenient and reliable technique for stablization of lingual retainer during bonding without the use of special instrument and is less time consuming. The technique also does not require the aid of an assistant.

\section{OJN}

\section{REFERENCES}

1. Beam DR. Bonded orthodontic retainers : A review. Am J Orthod Dentofac Orthop. 1995; 133:207-13.

2. Zachrisson BU. Long-term experience with direct-bonded retainers: update and clinical advice. J Clin Orthod. 2007; 41 (12):728-37.

3. Bishara SE, Treder JE, Damon P, Olsen M. Changes in the dental arches and dentition between 25 and 45 years of age. Angle Orthod. $1996 ; 66(6): 417-22$.

4. Booth FA, Edelman JM, Proffit WR. Twenty-year follow-up of patients with permanently bonded mandibular canine-to-canine retainers. Am J Orthod Dentofac Orthop. 2008; 133:70-6.

5. Durgekar SG, Nagaraj K, Upadhyay M, Yadav S. A simple technique for bonding lingual retainers. J Clin Orthod. 2010; 44(7):445-6.

6. Hattarki RS, Rastogi S. A simple technique for bonding lingual retainer. Int J Orthod 2015; 26(1):39-40. 